Escuela de Ciencias Sociales y Humanidades, UNED, C.R.

URL: http://investiga.uned.ac.cr/revistas/index.php/espiga/index

ISSN: 1409-4002 • e-ISSN: 2215-454X

Doi: http://dx.doi.org/10.22458/re.v17i35.1806

\title{
La situación de la trata de personas con fines de explotación sexual en México
}

\author{
María Rita Chávez-Gutiérrez* \\ (iD) https://orcid.org/0000-0001-6916-1724 \\ María Antonia Chávez-Gutiérrez** \\ https://orcid.org/0000-0001-8424-4317
}

Recibido: 05 de junio, 2017 - Aceptado: 29 de noviembre, 2017

«Donde existe la esclavitud, es denegada la dignidad humana y avergüenza a todos los que dicen ser misericordiosos o comprometidos con los débiles y vulnerables del mundo. Los derechos humanos no son otra cosa sino la insistencia en la erradicación de la esclavitud y de la coerción en todos los aspectos de la vida. Pero aun así, en el umbral del nuevo milenio, seguimos encontrando formas viejas y lamentablemente nuevas de esclavitud. Miles de personas de todo el mundo viven y mueren esclavos de una forma u otra.»

Kofi Annan

Sétimo Secretario General de las Naciones Unidas (1997-2006) y premio Nobel de la Paz, 2001

\section{Formato de citación según APA}

Chávez-Gutiérrez, M. R. y Chávez-Gutiérrez, M. A. (2018). La situación de la trata de personas con fines de explotación sexual en México. Revista Espiga 17(35), 31-44. Doi: http://dx.doi.org/10.22458/re.v17i35.1806

\section{Formato de citación según Chicago-Deusto}

Chávez-Gutiérrez, María Rita y María Antonia Chávez-Gutiérrez. «La situación de la trata de personas con fines de explotación sexual en México». Revista Espiga 17, n. ${ }^{\circ}$ 35 (junio, 2018): 31-44. Doi: http://dx.doi.org/10.22458/re.v17i35.1806

* Especialista en Derecho Social, especialista en Negociación Colectiva, maestra y doctora en Derecho. Miembro del Sistema Nacional de Investigadores (SNI), nivel 1. Profesora investigadora del Departamento de Desarrollo Social, del Centro Universitario de Ciencias Sociales y Humanidades (CUCSH), Universidad de Guadalajara, México. Correo: asesorchavezrita@yahoo.com.mx

** Licenciada en psicología, maestría en psicología educativa y doctorada en educación superior por la Universidad de Guadalajara. Profesora e investigadora Titular C, de tiempo completo en el Departamento de Desarrollo Social, división de Estudios Políticos y Sociales, en el Centro Universitario de Ciencias Sociales y Humanidades en la Universidad de Guadalajara, México. Correo: asesorachavez@gmail.com 


\section{RESUMEN}

Este artículo pretende describir la situación de la trata de personas con fines de explotación sexual en México, enfatizando la definición de los delitos, los medios y los fines y resultados en la operación del sistema de justicia en México. El artículo se sustenta en la teoría jurídica y de los derechos humanos; procura generar los aportes para optimizar la aplicación de la ley y su debida diligencia.

A lo largo del texto se explican las formas de esclavitud contemporánea, seguido de un acercamiento al contexto mundial de la trata de personas y los instrumentos jurídicos internacionales, identificando los corredores regionales de las redes de trata de personas en el mundo, para ubicar la trata de personas en México y el delito de trata de personas relacionados con la modalidad de explotación sexual en este país.

Palabras clave: trata de personas, explotacion sexual, México.

\section{Formas de esclavitud contemporánea}

Existen distintas formas denominadas de esclavitud contemporáneas, entre ellas la explotación sexual. Aun cuando existen los Convenios Internaciones sobre la Esclavitud de 1926, 1953 y 1956, así como el Estatuto de Roma de la Corte Penal Internacional de $1976^{1}$, en la actualidad hay muchas personas que viven alguna forma de esclavitud. En relación con este tema, Richard Re, en Harvard International Review ${ }^{2}$, documentó la existencia actual de 27 millones de esclavos contemporáneos en el mundo. De la misma forma, datos de la Organización Internacional del Trabajo (OIT) ${ }^{3}$ señalan que actualmente 21 millones de personas son víctimas del trabajo forzado, de los cuales 11,4 millones son mujeres y niñas, mientras que 9,5 millones son hombres y niños. Los más vulnerables son los trabajadores domésticos, los jornaleros agrícolas migrantes y los pueblos originarios, los asalariados de la construcción y manufactura, así como trabajadores de las empresas del entretenimiento. En este contexto, las empresas privadas explotan alrededor de 19 millones de trabajadores y dos millones por el Estado y grupos rebeldes; de los cuales 4,5 millones son víctimas del trabajo sexual forzado. Esto llega a producir 150 mil millones de dólares anuales.

En relación con la mendicidad forzada, el Fondo de las Naciones Unidas para la Infancia (UNICEF) ${ }^{4}$, estimó que 150 millones de niños entre 5 y 14 años realizan trabajos forzados y mendicidad forzada, pidiendo dinero a extraños, inspirando lástima,

1. David Weissbrodt, «La abolición de la esclavitud y sus formas contemporáneas», Oficina del Alto Comisionado de las Naciones Unidas para los Derechos Humanos (2002), acceso: 06 de abril de 2018, http://www.ohchr.org/Documents/Publications/slaverysp.pdf

2. Javier Barros del Villar, «Actualmente hay más esclavos que nunca. ¿Cuántos de ellos trabajan para ti?», PIJAMASURF: sociedad, activismo social, México (2013), acceso: 06 de abril de 2018, https://pijamasurf. com/2013/03/actualmente-hay-mas-esclavos-que-nunca-cuantos-de-ellos-trabajan-para-ti/

3. Organización Internacional del Trabajo (OIT), «Trabajo forzoso, tráfico humano y esclavitud» (2015), acceso: 06 de abril de 2018, http://www.ilo.org/global/topics/forced-labour/lang--es/index.htm

4. UNICEF, Informe del Fondo de las Naciones Unidad para la Infancia (2011), acceso: 06 de abril de 2018, https://www.unicef.org/lac/UNICEF_Annual_Report_2011_SP_053012.pdf 
vendiendo productos marginales por cooperación voluntaria y donativos que entregan a una tercera persona. Otra modalidad de esclavitud es el matrimonio servil ${ }^{5}$.

Al respecto, partir de 1924 la Comisión de las Naciones Unidas sobre la Esclavitud consideró como una forma de esclavitud la adquisición de niñas mediante compras simuladas en forma de pago de dote. Igualmente, desde 1956 fue sancionada esta práctica análoga a la esclavitud, cuando sin consentimiento de la mujer es prometida en matrimonio a cambio de dinero o especie; asimismo ocurrió con «el levirato», es decir, la trasmisión por herencia a la viuda. Ante estas barbaridades, en algunos países el Estado intervino con el establecimiento de reglas para garantizar la voluntad de la mujer y determinar una edad mínima para el matrimonio.

En el mismo sentido está la oferta de mujeres para el matrimonio a través de catálogos en las redes sociales. Esta práctica de explotación sexual pone en desventaja a la mujer cuando sale de su país, se le aleja de su familia y es sometida por el marido que las compra.

El matrimonio por complacencia es otra forma de esclavitud, cuando la mujer acepta casarse aunque no haga vida conyugal. De esta manera, forma parte del tráfico de migrantes y la trata de personas cuando es obligada a ganar dinero para su marido o para otra persona con la prostitución o con cualquier otra actividad remunerada. La fábrica de bebés es otra modalidad de trata, que consiste en embarazar mujeres -especialmente adolescentes- para traficar con bebés recién nacidos.

En este rango, el Foro de Viena para Combatir la Trata de Personas ${ }^{6}$ registró 36 mil millones de dólares en el negocio en torno de la trata de personas.

\section{Contexto mundial de la trata de personas y los instrumentos internacionales}

\section{Protocolos contra la trata y el tráfico}

Para hacer frente al fenómeno de la trata de personas, en el marco de las Naciones Unidas en el 2002 se emitió la Convención contra la Delincuencia Organizada Transnacional con dos instrumentos jurídicos: el Protocolo para Prevenir, Reprimir y Sancionar la Trata de Personas, Especialmente Mujeres y Niños, mejor conocido como «Protocolo de Palermo» del 2000, adoptado por México en 2003; asimismo, el Protocolo Contra el Tráfico Ilícito de Migrantes por Tierra, Mar y Aire del 2004.

Las conductas o acciones implicadas en los delitos de la trata de personas se relacionan con la inducción, promoción, distribución, comercialización, regenteo y uso de los servicios de la trata de personas: captación, transporte, traslado, acogida y recepción de las personas. Igualmente, la concesión, recepción de pago o beneficio para el consentimiento de una persona con autoridad sobre otra. Tratándose de menores de 18 años, se

5. Weissbrodt, «La abolición de...»

6. Foro de Viena para Combatir la Trata de Personas, ONU (2008), acceso: 06 de abril de 2018, http://www. ilo.org/global/about-the-ilo/newsroom/features/WCMS_090355/lang--es/index.htm 
incluye la captación, transporte, traslado, acogida y recepción con fines de explotación, sin que se haga uso de otras condicionantes delictivas. En el mismo sentido, en el tráfico de personas, las conductas facilitan la entrada ilegal de una persona no nacional o residente permanente a un Estado parte.

Los medios, son las herramientas, infraestructura, objetos, imágenes, sonidos, impresiones y situaciones de vulnerabilidad de los sujetos. Igualmente, el uso de amenazas, la fuerza, la coacción, el rapto, el fraude, el engaño, el abuso de poder y la vulnerabilidad en que se encuentre la víctima. En el tráfico de personas, las condiciones delictivas son documentos de identidad o de viaje falsos o cualquier forma ilegal para internarse al país receptor o de tránsito por mar, tierra o aire.

Los fines, describen las diversas formas de sumisión, explotación de personas u obtención de beneficios económicos. Desde esta perspectiva, el protocolo ${ }^{7}$ se refiere a los constitutivos de ambas figuras jurídicas, la trata y el tráfico de personas. La explotación, la prostitución u otras formas de explotación sexual, los trabajos y los servicios forzados, la esclavitud, la servidumbre o la extracción de órganos. Específicamente en el tráfico de personas, el fin es la obtención directa o indirecta de un beneficio material o financiero.

La ley hace hincapié en que la atención de las víctimas estará a cargo del Estado y las organizaciones civiles, quienes se encargarán de la atención biopsicosocial, médica y material de las víctimas. Se proporcionará alojamiento, oportunidad de empleo, educación y capacitación. Del mismo modo, se asegurará la permanencia temporal y permanente en el territorio cuando proceda. En relación con el tráfico de personas, la atención se refiere a la prevención y el combate del tráfico ilícito de migrantes con la cooperación internacional y el respeto absoluto de los derechos individuales.

\section{Protección de mujeres y niños contra la explotación sexual}

Existen varios convenios relacionados con la Represión de la Trata de Blancas, de 1907 y 1910, y la Convención Internacional Relativa a la Represión de la Trata de Mujeres Mayores de Edad, en Ginebra en 1933, al cual México se adhirió en 1938. Cabe mencionar la Convención de Belem Do Para de 1994, de la Convención Interamericana para Prevenir, Sancionar y Erradicar la Violencia contra la Mujer, adoptada por México en 1998. La Convención sobre los Derechos del Niño, en Nueva York en 1989, incorporado por México en 1999; el Convenio de la Organización Internacional del Trabajo (OIT) número 182, sobre la Prohibición de las Peores Formas de Trabajo Infantil y la Acción Inmediata para su Eliminación, en Ginebra en 1999, adoptado por México en 2001. Además, está el Protocolo Facultativo de la Convención sobre los Derechos de los Niños relativo a la venta de niños, la prostitución infantil y la utilización de niños en pornografía, en Nueva York en el 2000, adoptado por México el mismo año.

7. Protocolo para prevenir, reprimir y sancionar la trata de personas, especialmente mujeres y niños, que complementa la Convención de las Naciones Unidas contra la Delincuencia Organizada Transnacional (2000), acceso: 06 abril de 2018, https://www.poder-judicial.go.cr/accesoalajusticia/index. $\mathrm{php} /$ normativa-violencia-sexual/category/153-instrumentos-internacionales?download=996:protoco lo-prevenir-reprimir-sancionar-trata-personas 
De data reciente son el Código de Conducta para la Protección de los Niños frente a la Explotación Sexual en el Turismo y en la Industria de Viajes, de la Organización Mundial de Turismo, en el 2003, el Programa Internacional contra el Trabajo Infantil (IPEC) en el 2000, el Foro de Viena de Enfrentamiento a la Trata de personas en el 2008 y el Código Nacional de Conducta para la Protección de Niñas, Niños y Adolescentes en el Sector de los Viajes y el Turismo en el 2015. No obstante los esfuerzos internacionales de los países para ponerse de acuerdos a través de convenios, convenciones, pactos y protocolos con el fin de frenar el fenómeno de la explotación de seres humanos, las conductas atávicas de insensibilidad humana los han rebasado, debido a los grandes capitales provenientes de la trata de personas.

\section{Corredores regionales de las redes de trata de personas en el mundo}

La trata de personas transnacional se calcula entre dos y cuatro millones de personas anualmente, entre 800 mil y 900 mil sufren explotación laboral y sexual (98\%), mientras $55 \%$ de la explotación laboral son mujeres y niñas. Es decir, en todas las formas de trata de personas predomina el $98 \%$ del género femenino.

\section{Trata de personas en Europa, Asia Central, África y Medio Oriente}

En Europa y Asia Central se detectó 66\% de víctimas de trata de personas; $82 \%$ adultos y $18 \%$ menores. Esta zona geográfica queda en el polígono de Europa, a partir de Islandia, Grecia, Portugal y Ucrania. En esta misma región, 39 países de Europa Occidental, desde Islandia, Noruega, Reino Unido, Francia, España, hasta Italia, así como Europa Central, a partir de Alemania, Polonia, Suiza, Austria, hasta Hungría, han tipificado la mayoría de los delitos de trata personas. En Oriente Medio y África del Norte, 230 mil personas trabajan en condición de trata de personas. En tanto, en África subsahariana suman 130 mil personas. En esta región, se reveló la existencia de 53\% de las víctimas. Aquí son más niños (62\%), frente a $38 \%$ de adultos.

\section{Trata de personas en América, Asia Meridional y el Pacífico}

En toda Latinoamérica ${ }^{8}$ suman 108 millones víctimas de trata de personas. En América Latina y el Caribe, el trabajo forzado como consecuencia de la trata de personas asciende a 250 mil personas. Ahora bien, resulta que 18 países han tipificado todos los delitos de trata de personas; un país lo ha hecho en forma parcial y uno no tipificó este delito. En América del Sur, ocho países han incluido la mayoría de los delitos y tres lo han hecho en forma parcial. En toda la zona de Asia Pacífico existen 11,7 millones de víctimas, específicamente en Asia Meridional y el Pacífico. Según datos de la Oficina de las Naciones Unidas contra la Drogas y el Delito 2014 (UNODC) ${ }^{9}$, se señala que trabajan en condición de trata un millón 360 mil personas.

8. Foro de Viena para Combatir la Trata de Personas, ONU (2008).

9. «Diagnóstico nacional sobre la situación de la trata en México», UNODC, Oficina de las Naciones Unidas contra la Droga y el Delito (2014), acceso: 06 de abril de 2018, https://www.unodc.org/documents/ mexicoandcentralamerica/Diagnostico_trata_de_personas.pdf 


\section{Trata de personas en México}

\section{Proceso del enganche}

La trata de personas hace del comercio de seres humanos un negocio lucrativo, difícil de erradicar por su complejidad social política y jurídica. Alude a un modelo económico inequitativo, generador de pobreza, marginación, regímenes de bienestar excluyentes, violencia e ignorancia, y un deficiente sistema de procuración de justicia.

En este contexto, las víctimas de trata de personas, ante condiciones precarias de subsistencia, se enrolan en promesas de acceso a mejores condiciones de vida, estatus de reconocimiento social que supuestamente superarán la violencia, la discriminación y la exclusión social soportada. Los tratantes, se aprovechan de los estados psicológicos depresivos de las víctimas, precarización afectiva, la falta de capacidad de discernimiento acerca de su identidad, el entorno y la fe religiosa, quedando sujetos a sistemas con deficiencia legislativa e ineficacia de las leyes en la protección de los derechos humanos, así como la impunidad y la corrupción en el manejo de denuncias y desatención a las víctimas.

Los tratantes suelen ser familiares o amigos de la víctima; pueden operar en forma individual, en redes de intermediarios, contratistas y delincuencia organizada. Existen entornos que facilitan el proceso de reclutamiento: familia, amigos, redes sociales y medios impresos y electrónicos, seducidos por propuestas de atractivas oportunidades laborales, educativas, religiosas y matrimoniales, así como facilidades para traslados legales e ilegales.

En México, en el informe de la Comisión Nacional de Derechos Humanos ${ }^{10}$, con datos de la Fiscalía Especial para Delitos de Violencia en contra de las Mujeres y Trata de Personas de 2014 (CNDH-FEVIMTRA), se enuncia que el 45\% de las víctimas son captadas por un conocido (familiar pariente lejano, amigo o pareja), $49 \%$ por desconocidos y 5,5\% por secuestro de la delincuencia organizada; se destaca a las mujeres como enganchadoras, a las víctimas se les violan sus derechos humanos y sufren afecciones en su salud física y mental, pues, una vez captadas, se les aleja de su entorno social, se les amenaza, extorsiona y despoja de documentos y bienes personales; se retienen salarios o pagos, las inducen a las drogas, las privan de la libertad, las someten a la esclavitud o las asesinan.

Ciertamente México es un país de origen, tránsito y destino de trata de personas y de migrantes legales e ilegales; ocupa el segundo lugar del mundo como proveedor de víctimas a Estados Unidos de América y como principal consumidor mundial de personas en condición de explotación. En México no hay datos estadísticos certeros acerca de la trata de personas, en virtud de las condiciones de clandestinidad, corrupción y complicidad que ocultan la realidad del fenómeno. Oficialmente, la $\mathrm{CNDH}^{11}$ y la FEVIMTRA ${ }^{12}$

10. CNDH, Informe de la Comisión Nacional de Derechos Humanos, México, 2014, acceso: 06 de abril de 2018, http://www.cndh.org.mx/sites/all/doc/informes/anuales/2014.pdf

11. Ibíd.

12. Fiscalía Especializada para los Delitos en contra de las Mujeres y Trata de Personas, FEVIMTRA (2014), acceso: 06 de abril de 2018, http://www.pgr.gob.mx/Fiscalias/fevimtra/Paginas/default.aspx 
describen varios aspectos. Según el perfil de las víctimas, 83\% son mujeres, 14\% son hombres y el 3\% se desconoce. En cuanto a la edad, $42 \%$ son adultos, $40 \%$ niñas, niños y adolescentes, $18 \%$ se desconoce. Con relación al origen de las víctimas, $78 \%$ son mexicanas, $15 \%$ extranjeras y $7 \%$ desconocido.

\section{Complejidad legal}

En el sistema jurídico de México concurren legislaciones inconexas, sujetas al fuero federal o común; también hay una falta de capacitación en las autoridades y funcionarios públicos. En definitiva, la corrupción y la impunidad fluyen desde arriba hacia abajo en la administración de la justicia, de manera que el acceso a ella se convierte en una complicación difícil que dificulta más el cumplimiento de la ley.

\section{Identificación de víctimas}

Acerca de las víctimas de trata de personas en México, según información del Diagnóstico Nacional sobre la Situación de Trata de Personas en México, formulado por la Oficina de las Naciones Unidas contra la Droga y el Delito en 2011 (UNODC) ${ }^{13}$, con datos del Instituto Nacional de Migración (INM), Oficina de la Fiscalía Especializada para la Violencia contra la Mujer y el Tráfico de Personas (FAVIMITRA), la Subprocuraduría Especializada en Investigación de la Delincuencia Organizada de la Procuraduría General de la República (SEIDO PGR) y la Unidad Especializada en la Investigación de Tráfico de Menores, Personas y Órganos y el informe de la Comisión Nacional de Derechos Humanos 2013 (CNDH, 2014); del periodo 2010 a 2013, apenas se logró identificar 724 víctimas: 354 mexicanas, 204 guatemaltecas, 76 hondureñas, 20 colombianas y 20 haitianas. Cabe mencionar que en estos dos años, únicamente se condenó a siete delincuentes. Por último, el informe de la CNDH, se señala que en 2013 aumentó a 250 las víctimas localizadas: mayormente mujeres (141) y niñas (58), en comparación con menos hombres (2) y niños (22). En este mismo año, se sentenció a 56 personas. Igualmente la PGR informó que estuvieron en proceso legal 259 presuntos delincuentes, en relación con 136 casos, aunque solo el $26 \%$ fue condenado.

\section{Seguimiento procesal}

Informes recibidos por las CNDH en el 2013, provenientes de las distintas autoridades judiciales, arrojaron los siguientes resultados: 1101 averiguaciones previas, 454 consignaciones, 50 expedientes de no ejercicio de la acción penal, 58 casos archivados con la reserva de ley para encontrar más pruebas y en 93 sentencias no se precisa en qué sentido y por qué delitos. Sólo hubo tres sentencias condenatorias a nivel federal y 90 en el

13. «Diagnóstico nacional sobre...» 
orden local (estados). Igualmente, la PGR, en 2014, informó que lleva 91 averiguaciones previas, 62 ya terminadas, pero no se sabe su culminación ${ }^{14}$.

Existe un déficit en la procuración, aplicación y ejecución de la justicia en materia de trata, que se explica por una serie de ineficiencias e ineficacias en la justicia administrativa y justicia penal. Existe falta de sensibilidad y conocimiento especializado en los operadores de la procuración de justicia. Los agentes del ministerio público dejan endebles las averiguaciones previas y los jueces hacen lo mismo con las sentencias, en razón de que carecen de la sensibilización y capacitación técnica acerca de la teoría y la fenomenología del delito, así como del perfil de las víctimas o por impunidad y corrupción. Falta pericia para revisar la congruencia entre las normas nacionales y la Convención Americana de los Derechos Humanos, la aplicación de las herramientas periciales, los tratados internacionales, el enfoque de los derechos humanos, la perspectiva de género y la protección integral de los derechos de las niñas, niños y adolescentes.

\section{Lento proceso de armonización a la Ley General}

En México, la Ley General para Prevenir, Sancionar y Erradicar los Delitos en Materia de Trata de Personas y para la Protección y Asistencia a las Víctimas de estos Delitos (Ley General) es de aplicación en todo el territorio a partir del 14 de junio de 2012.

En los estados existen 24 leyes estatales no todas armonizadas, en razón de que algunos estados no están de acuerdo con reproducir las deficiencias de la ley general o no quieren comprometerse en las acciones conjuntas de aplicación general y prefieren seguir aplicando sus códigos penales o sus leyes estatales vigentes anteriores a la Ley General.

Los 11 estados de la República (34.38\%) que ya armonizaron sus leyes a la Ley General desde 2012, son: Baja California (2013), Chiapas (octubre, 2012), Coahuila (noviembre, 2012), Durango (junio, 2012), Jalisco (septiembre, 2012), Estado de México (2013), Oaxaca (junio, 2012), Puebla (diciembre, 2012), Querétaro (diciembre, 2012), Quintana Roo (2014) y Veracruz (2013), Distrito Federal (2008), Guerrero (2011), Hidalgo (2010), Michoacán (febrero, 2012), Nayarit (2011), Nuevo León (2010), San Luis Potosí (2011), Sinaloa (2011), Sonora (2011), Tabasco (2009), Tamaulipas (2010), Tlaxcala (2011) y Yucatán (2011). Siete estados (21,88\%) carecen de legislación sobre la trata: Aguascalientes, Baja California Sur (lo tipifica como no grave en el código penal), Campeche, Chihuahua, Colima, Guanajuato y Zacatecas.

Estas irregularidades facilitan a los perpetradores sortear la impunidad, transitan entre los estados que no tipifican la trata, los que no la han armonizado o los que la identifican con conductas punibles no graves, incluyendo los estados donde haya más corrupción e impunidad.

14. Majo Siscar, «Estas son las rutas de la explotación sexual en México», Animal Político (2014), acceso: 06 de abril de 2018, https://www.animalpolitico.com/2014/09/mexico-exporta-e-importa-victimas-de-trataconoce-las-rutas-de-la-explotacion-sexual/ 


\section{Del delito de trata de personas relacionados con la modalidad de explotación sexual en México}

En México, la Ley General para Prevenir, Sancionar y Erradicar los Delitos en Materia de Trata de Personas ${ }^{15}$ y para la Protección y Asistencia a las Víctimas de estos Delitos del 2012, define la trata en términos de explotación:

Toda acción u omisión dolosa de una o varias personas para captar, enganchar, transportar, transferir, retener, entregar, recibir o alojar a una o varias personas con fines de explotación se le impondrá de 5 a 15 años de prisión y de un mil a veinte mil días multa, sin perjuicio de las sanciones que correspondan para cada uno de los delitos cometidos, previstos y sancionados en esta Ley y en los códigos penales correspondientes (artículo10).

Según el Protocolo de Palermo, la trata de personas es un delito autónomo de resultado anticipado. Hay que remitirse al catálogo de los delitos de la trata de personas: esclavitud, servidumbre, explotación sexual (pornografía y prostitución), turismo sexual, explotación laboral y trabajos forzados. La mendicidad forzada, la utilización de menores de edad en actividades delictivas, la adopción ilegal de menores de edad, el matrimonio forzado o servil, el tráfico de órganos, tejidos y células de seres humanos y la experimentación biomédica ilícita en seres humanos (artículos 10 y 11). A continuación se explican los tipos penales de solo algunas de las modalidades.

\section{De la esclavitud}

En concordancia con las convenciones internacionales, la Constitución Política de México ${ }^{16}$ prevé la prohibición de la esclavitud: «Está prohibida la esclavitud en los Estados Unidos Mexicanos. Los esclavos del extranjero que entren al territorio nacional alcanzarán, por este solo hecho, su libertad y la protección de las leyes» (artículo1 ${ }^{\circ}$ : c).

La Ley General considera esclavitud la conducta punible referida al dominio de una persona sobre otra, impidiéndole ejercer el derecho a decidir sobre su persona y sus bienes y atribuyéndose derechos de propiedad sobre ella (artículos 10 y 11).

No obstante su prohibición legal, México ostenta el primer lugar en América Latina del Índice Global de Esclavitud (2014), con al menos 266900 personas explotadas en la agroindustria, la minería y el turismo. Ocupa el lugar 18 del ranking mundial de esclavitud entre 166 países. Solo lo superan India, China, Pakistán, Uzbekistán, Rusia, Nigeria, República Democrática del Congo, Indonesia, Bangladesh, Tailandia, Sudán, Egipto, Etiopía, Iraq, Irán y Vietnam ${ }^{17}$.

15. Ley General para Prevenir, Sancionar y Erradicar los Delitos en Materia de Trata de Personas y para la Protección y Asistencia a las Víctimas de estos Delitos (2012), México, acceso: 06 de abril de 2018, http:// www.diputados.gob.mx/LeyesBiblio/ref/lgpsedmtp.htm

16. Constitución Política de los Estados Unidos Mexicanos, 1917 (2016), acceso: 06 de abril de 2018, http:// www.ordenjuridico.gob.mx/Constitucion/cn16.pdf

17. Tania L. Montalvo, «Esclavitud aún en 2015, México tiene el índice más alto en América Latina», Animal Político (30 de marzo, 2015), México, acceso: 06 de abril de 2018, https://www.animalpolitico.com/2015/03/ mexico-el-pais-de-america-latina-con-el-indice-mas-alto-de-esclavitud/ 


\section{De la explotación sexual}

\section{Situación legal}

Se considera explotación sexual cuando una o varias personas realizan una acción u omisión dolosa para captar, enganchar, transportar, transferir, retener, entregar, recibir o alojar a una o varias personas con el fin de obtener un beneficio libidinoso. La Ley General $^{18}$ prevé el engaño, el aprovechamiento de la vulnerabilidad de la víctima, la violencia física o moral, la amenaza de daño grave y el abuso del poder.

El mismo numeral incluye el daño grave, la amenaza de denuncia ante autoridades respecto a su situación migratoria en el país o cualquier otro abuso de la utilización de la ley o procedimientos legales que provoquen que el sujeto pasivo se someta a las exigencias del activo. Tratándose de personas menores de edad o personas que no tienen la capacidad de comprender el significado del hecho, no se requiere la comprobación de estas condicionantes delictivas.

El fin de la explotación sexual es la prostitución ajena o cualquier otra actividad sexual remunerada. A esta, se agrega la pornografía, las exhibiciones públicas o privadas de orden sexual y el turismo sexual aunque este último solo se mencione en relación con los menores de edad y no haya una definición de aplicación general (artículos13 y 20).

\section{De la pornografía}

Por el exhibicionismo corporal con fines sexuales, la Ley General establece penas de 10 a 15 años de privación de la libertad; por la comercialización es de 5 a 10 años y las agravantes van de 15 a 30 años de prisión. En relación con este delito, en 2004 la Secretaría de Seguridad Pública Federal ubicó 14 millones de sitios pornográficos en redes, con creación de 500 sitios nuevos diarios. Sin embargo, solo desmanteló 300 sitios de internet sobre pornografía infantil, detuvo a 66 presuntos traficantes y rescató a 104 menores.

\section{De la prostitución}

La prostitución bajo coacción significa engañar a una persona para que preste servicios sexuales. La pena es de 5 a 10 de prisión. En condición de trata, son las conductas de quien promueve, facilite o contribuya con la prostitución de personas de uno u otro sexo, o la que obligue a permanecer en ella con la utilización de medios como el engaño, el abuso de una situación de necesidad o vulnerabilidad, de una relación de dependencia o de poder, la violencia, la amenaza o cualquier otro medio de intimidación o coerción; esto con el fin de satisfacer deseos ajenos o con ánimo de lucro o beneficio.

Se considera prostitución ajena el regenteo o la administración directa o indirecta de prostíbulos, casas de cita o lugares de concurrencia expresamente dedicados a explotar la prostitución. Se impondrá pena de 15 a 30 años de prisión cuando se trate de una persona menor de 18 años de edad o que no tenga la capacidad de comprender el significado del hecho ni capacidad de resistir la conducta.

18. Ley General para Prevenir... 
En la ley no se define el turismo sexual en general, solo se considera como turismo sexual la promoción de viajes al interior y exterior del territorio para la realización de actos sexuales con menores e incapaces; por lo que, por estas conductas, se aplicará de 15 a 25 años de prisión (artículo 18). Solo se define el turismo sexual de menores de edad e incapaces, donde no incluye a los adultos capaces. Asimismo, castiga al que se beneficie de la explotación, pero no castiga al que compra estos servicios.

México se ha considerado paraíso del turismo sexual en los puertos turísticos, fronteras, ciudades medias y grandes. Se ofertan estos servicios en Estados Unidos de América, Canadá y Europa Occidental. Del mismo modo, estos servicios también los pagan los consumidores clientes explotadores locales como taxistas, policías, oficinistas, pescadores, trabajadores de los hoteles y agentes turísticos. Es decir, lo disfrutan personas de todas las clases sociales.

\section{De los contratos laborales con inducción sexual}

Se trata del beneficio económico de los contratos lícitos de prestación laboral, que posteriormente se induce mediante el engaño a realizar actos que por su naturaleza, condiciones y circunstancias sean sexuales, también cuando se obliga a realizarlos a cambio de saldar una deuda o pagar por su libertad de dejar el trabajo o salir de su lugar de residencia. Será sancionado con penas de 5 a 10 años de prisión (artículo 19).

En este supuesto, se castiga el artificio para que la persona contratada para desempeñar un trabajo legal comprometa su cuerpo en contra de su voluntad. Sin embargo, se considera que esta figura debería estar en la ley del trabajo no en la ley de trata. Este tipo de contratos se ofrecen a hombres jóvenes desempleados o con estudios profesionales para trabajar en empresas turísticas, hospitales, cadenas de hotelería, gimnasios, guardias personales, cruceros o cualquier empresa supuestamente exitosa.

\section{Conclusiones y propuestas}

En México existe un déficit en la procuración, aplicación y ejecución de la justicia en materia de trata de personas, esto se explica por una serie de ineficiencias e ineficacias en la justicia administrativa y justicia penal. Existe falta de sensibilidad y conocimiento especializado en los operadores de la procuración de justicia. Los agentes del ministerio público dejan endebles las averiguaciones previas y los jueces hacen lo mismo en las sentencias, en razón de que carecen de la sensibilización y capacitación técnica acerca de la teoría y la fenomenología del delito y el perfil de las víctimas o por impunidad y corrupción. Falta pericia para revisar la congruencia entre las normas nacionales y la Convención Americana de los Derechos Humanos, la aplicación de las herramientas periciales, los tratados internacionales, el enfoque de los derechos humanos, la perspectiva de género y la protección integral de los derechos de las niñas, niños y adolescentes.

Aunque discrepantes, en México los datos de los distintos informes sobre trata de personas consultados para la realización de este articulo (Comisión de Derechos Humanos, 
informe 2014, Fiscalía Especializada para los Delitos en contra de las Mujeres y Trata de Personas, infome 2014 y Oficina de las Naciones Unidas contra la Droga y el Delito, informe 2014) se centran más en la trata de personas en modalidad de explotación sexual, con poca o nada de información acerca de las otras modalidades. Por lo que se precisa un diagnóstico general acerca de los once delitos de trata de personas.

En el sistema jurídico mexicano concurren legislaciones inconexas, sujetas al fuero federal o común, así como la falta de capacitación en las autoridades y funcionarios públicos, donde confluyen la corrupción y la impunidad en las instancias de administración de la justicia, que hacen más complicado el cumplimiento de la ley.

Por tanto, las políticas públicas y la intervención de los diversos sectores de sociedad tendrán que realizar acciones contundentes para exigir y hacer viable el acceso a la justicia pronta y expedita para los damnificados de los delitos de trata de personas y para castigar la impunidad y la corrupción.

Con esta perspectiva, las autoridades judiciales deberán dar cuenta de sus competencias y capacidades para aplicar el control difuso de la convencionalidad de los tratados internacionales en materia de trata de personas; asimismo, para interpretar directamente la Constitución y las normas internacionales sobre derechos humanos que se integran con el rango constitucional.

En el mundo que nos alberga, solo un cambio civilizatorio desde el desarrollo humano permitirá trascender de la explotación del semejante hacia el respeto de la dignidad del otro.

Pareciera que la inclusión de la mayoría de las modalidades de trata de personas en las legislaciones de las regiones del mundo no ha impactado en su erradicación como se prevé en los acuerdos vinculantes. Esto indica que a la par de los acuerdos internacionales, es impostergable la voluntad política de los organismos internacionales y de los países consumidores para enfrentar esta forma de esclavitud; así como el compromiso de los países de origen y tránsito por intervenir en las causas de la trata de personas y mejorar los regímenes de bienestar y la aplicación efectiva de la atención integral a las víctimas de estos delitos.

\title{
ABSTRACT
}

\section{The situation of human trafficking for sexual exploitation in Mexico}

\begin{abstract}
This article aims to describe the situation of human trafficking for sexual exploitation in Mexico, emphasizing the definition of the crimes, the means, ends and results in the operation of the Mexican judicial system. The article is based on legal and human rights theory; it aims to generate contributions to optimize the application of the law and its due diligence.

The text explains contemporary forms of slavery followed by an approach to the global context regarding human trafficking and international legal instruments. It also identifies the regional corridors for human trafficking networks in the world in order to locate human trafficking in Mexico, and human trafficking crimes related to sexual exploitation in this country.
\end{abstract}

Key words: human trafficking, sexual exploitation, Mexico. 


\section{La situation de la traite des personnes à des fins d'exploitation sexuelle au Mexique}

Cet article vise à décrire la situation de la traite des personnes à des fins d'exploitation sexuelle au Mexique portant sur la définition des crimes, des moyens et fins, et les résultats de l'opération du système de justice au Mexique. L'article s'appuie sur des premisses des théories juridiques et les droits humains afin de générer des apports pour optimiser l'application de la loi et sa diligence. $\mathrm{Au}$ fil du texte, les formes d'esclavage moderne sont expliquées ainsi que le contexte mondial de la traite des êtres humains et les instruments juriques internationaux. En plus, les passeurs clandestins regionaux des resaux de traites des êtres humains du monde sont identifiés afin de situer au Mexique la traite des êtres humains et les crimes d'exploitation sexuelle liés à ce phénomène.

Mots clés: traite des personnes, exploitation sexuelle, Mexique.

\section{Bibliografía}

Acuerdo Internacional para la Supresión del Tráfico de Trata de Blancas (1904) [1949] [1950]. Acceso: 12 de abril de 2018. http://www.derecho.unam.mx/cultura-juridica/pdf/onu-1.pdf

Barros del Villar, Javier. «Actualmente hay más esclavos que nunca. ¿Cuántos de ellos trabajan para ti?», Pijamasurf: sociedad, activismo social. México (2013). Acceso: 12 de abril de 2018. https://pijamasurf. com/2013/03/actualmente-hay-mas-esclavos-que-nunca-cuantos-de-ellos-trabajan-para-ti/

Constitución Política de los Estados Unidos Mexicanos, 1917 (2014). Acceso: 12 de abril de 2018. http://www. ordenjuridico.gob.mx/Constitucion/cn16.pdf

Convención Interamericana para Prevenir, Sancionar y Erradicar la Violencia contra la Mujer. «Convención de Belem Do Para» (1994). Acceso: 12 de abril de 2018. http://www.oas.org/juridico/spanish/tratados/a-61. html

Fiscalía Especializada para los Delitos en contra de las Mujeres y Trata de Personas (FEVIMTRA), 2014. Acceso: 12 de abril de 2018. http://www.pgr.gob.mx/Fiscalias/fevimtra/Paginas/default.aspx

Foro de Viena para Combatir la Trata de Personas, ONU (2008). Acceso: 12 de abril de 2018. http://www.ilo. org/global/about-the-ilo/newsroom/features/WCMS_090355/lang--es/index.htm

Montalvo, Tania L. «Esclavitud aún en 2015: México tiene el índice más alto en América Latina». Animal Político, 30 de marzo de 2015. Acceso: 12 de abril de 2018. https://www.animalpolitico.com/2015/03/ mexico-el-pais-de-america-latina-con-el-indice-mas-alto-de-esclavitud/

Organización Internacional del Trabajo. «Trabajo forzoso, tráfico humano y esclavitud», 2015. Acceso: 12 de abril de 2018. http://www.ilo.org/global/topics/forced-labour/lang--es/index.htm

Programa Internacional contra el Trabajo Infantil (IPEC), 2000. Acceso: 12 de abril de 2018. http://www.ilo. org/ipec/lang--es/index.htm

Protocolo Contra el Tráfico Ilícito de Migrantes por Tierra, Mar y Aire, que complementa la Convención de las Naciones Unidas contra la Delincuencia Organizada Transnacional, 2000. Acceso: 12 de abril de 2018. http://www.oas.org/juridico/spanish/tratados/sp_proto_cont_tr $\% \mathrm{C} 3 \% \mathrm{~A} 1 \mathrm{fi}$ _1 \%C3\%ADci_migra_tierra_ mar_aire_comple_conve_nu_cont_delin_orga_transn.pdf

Protocolo Facultativo de la Convención sobre los Derechos de los Niños relativo a la Venta de Niños, la Prostitución Infantil y la Utilización de Niños en Pornografía, 2000. Acceso: 12 de abril de 2018. http://200.33.14.34:1033/archivos/pdfs/Var_52.pdf

Protocolo para Prevenir, Reprimir y Sancionar la Trata de Personas, Especialmente Mujeres y Niños, que complementa la Convención de las Naciones Unidas contra la Delincuencia Organizada 
Transnacional, 2000. Acceso: 12 de abril de 2018. https://www.poder-judicial.go.cr/accesoalajusticia/index.php/normativa-violencia-sexual/category/153-instrumentos-internacionales?download=996:protoco lo-prevenir-reprimir-sancionar-trata-personas

Siscar, Majo. «Estas son las rutas de la explotación sexual en México». Animal Político, 24 de septiembre de 2014. Acceso: 12 de abril de 2018. http://www.animalpolitico.com/2014/09/ mexico-exporta-e-importa-victimas-de-trata-conoce-las-rutas-de-la-explotación-sexual

UNICEF. Informe del Fondo de las Naciones Unidad para la Infancia, 2011. Acceso: 12 de abril de 2018. https://www.unicef.org/lac/UNICEF_Annual_Report_2011_SP_053012.pdf

Oficina de las Naciones Unidas contra la Droga y el Delito (UNODC). «Diagnóstico Nacional sobre la situación de la trata en México», 2014. Acceso: 12 de abril de 2018. https://www.unodc.org/documents/ mexicoandcentralamerica/Diagnostico_trata_de_personas.pdf

Weissbrodt, David. «La abolición de la esclavitud y sus formas contemporáneas». Oficina del Alto Comisionado de las Naciones Unidas para los Derechos Humanos, 2002. Acceso: 12 de abril de 2018. http://www. ohchr.org/Documents/Publications/slaverysp.pdf 